\title{
Tolerancia religiosa en el republicanismo. El caso de Carlos E. Restrepo ${ }^{1}$
}

\section{Resumen}

Este escrito presenta, a grandes rasgos, la ideología que en materia de tolerancia religiosa tenía el movimiento político denominado republicanismo a principios del siglo XX en Colombia. De manera especial, se concentra en los escritos del expresidente Carlos Eugenio Restrepo. En el texto se resumen las dificultades de este líder antioqueño por separar del ejercicio político las diatribas religiosas, su lucha por que fueran aceptadas personas no católicas dentro de la Unión Republicana, el apoyo que le dio a los misioneros protestantes que llegaron a Medellín, y en general, su apertura a otras ideas religiosas diferentes al catolicismo romano. El texto plantea que la relación conservatismo-Iglesia católica no tiene un solo color (los conservadores aliados políticamente con los clérigos), y que es necesario ampliar la escala de análisis hasta el punto de las relaciones personales para percibir ciertos matices.

Palabras clave: Colombia, política, religión, protestantismo, tolerancia.

Referencia para citar este artículo: CARBALLO, Fabio Hernán (2016). "Tolerancia religiosa en el republicanismo. El caso de Carlos E. Restrepo". En Anuario de Historia Regional y de las Fronteras. 21 (2). pp. 249-263.

Fecha de recepción: 30/11/2015

Fecha de aceptación: 18/02/2016

Fabio Hernán Carballo: Magíster en Historia, Universidad de Antioquia. Historiador, Universidad de Antioquia. Profesor de cátedra, Universidad de Antioquia y Universidad Pontificia Bolivariana, sede Medellín. Correo electrónico: carballo1602@gmail.com.

Este escrito se presentó en el coloquio Pluralismo, diversas espiritualidades y convivencia, en la ciudad de Medellín el día 14 de noviembre del 2014. 


\title{
Religious Tolerance in Republicanism. Carlos E. Restrepo's Case
}

\begin{abstract}
This paper depicts, in broad terms, the ideology on religious tolerance that the political movement called Republicanism had in the early $20^{\text {th }}$ century in Colombia. In particular, it focuses on the writings of former President Carlos Eugenio Restrepo. The text summarizes the difficulties of this leader born in Antioquia to segregate religious diatribes from the political exercise, its struggle for non-Catholic people to be accepted within the Republican Union, the support that gave the Protestant missionaries who arrived in Medellin and, in general, his openness to other religious ideas different to the ones from Roman Catholicism. The text states that the relationship between conservatism and the Catholic Church (conservatives politically allied with the clerics) does not have a single color, and that it is needed to expand the analysis scale to the point of personal relationships in order to perceive certain nuances.
\end{abstract}

Keywords: Colombia, Politics, Religion, Protestantism, Tolerance.

\section{Tolerância religiosa no republicanismo. $O$ caso de Carlos E. Restrepo}

\section{Resumo}

Este escrito apresenta, de forma geral, a ideologia que em matéria de tolerância religiosa tinha o movimento político denominado republicanismo, a começos do século XX na Colômbia. De forma especial, concentra-se nos escritos do ex-presidente Carlos Eugenio Restrepo. O texto resume as dificuldades deste lider antioquenho por separar do exercício politico as diatribes religiosas, sua luta para que as pessoas não católicas fossem aceitas dentro da União Republicana, o apoio que deu aos missioneiros protestantes que chegaram a Medellin e, em geral, sua abertura a outras idéias religiosas diferentes ao catolicismo romano. $O$ texto expõe que a relação conservadorismo-Igreja católica não tem apenas um tom (os conservadores aliados politicamente com os clérigos) e que é necessário ampliar a escala de análise até o ponto das relações pessoais para perceber certos nuances.

Palavras chave: Colombia, política, religião, protestantismo, tolerância. 


\section{Introducción}

El político conservador moderado Carlos Martínez Silva decía a finales del siglo XIX que la bandera de la religión había sido la principal causa de las guerras en Colombia. Liberales y conservadores defendían sus ideas como verdades absolutas donde el otro tenía que ser convencido de su error o morir en el intento. Según Martínez Silva, desde mediados de siglo, cuando los partidos apenas se configuraban, la intransigencia religiosa reinó en medio del caos institucional ${ }^{2}$.

Martínez Silva hacía parte del grupo de conservadores disidentes conocidos como históricos. Evidentemente, le preocupaba la cuestión religiosa, creía en la independencia de las dos potestades, Iglesia y Estado, “[...] mediando entre ellas relaciones de amistad y delimitándose el campo de sus derechos y deberes respectivos y recíprocos"3. El periodista y político santandereano no fue el único conservador que buscó una salida a lo que algunos de sus copartidarios llamaban el fanatismo. Después de su muerte, en 1903, un renovado grupo de disidentes conservadores asumieron el papel de opositores, esta vez al gobierno de Rafael Reyes. A esta ala conservadora se le dio el nombre de unión republicana o republicanismo. Su mayor representante fue el antioqueño Carlos Eugenio Restrepo. El ideal de república de Restrepo pasaba por el acuerdo de los dos partidos en asuntos de Estado y por separar el discurso religioso de la práctica política.

\section{Contactos entre Carlos E. Restrepo y ministros protestantes}

El 21 de diciembre de 1922 el misionero protestante Tomas E. Barber, quien trabajaba como pastor de la iglesia presbiteriana en Medellín, le regaló una biblia al expresidente Carlos E. Restrepo en nombre de la Sociedad Bíblica Americana a la cual representaba. En la nota adjunta al regalo, el ministro norteamericano le agradecía al Dr. Restrepo su labor a favor de la justicia y los derechos de la humanidad, le expresaba que las Sagradas Escrituras habían sido la base de la justicia y los derechos del pueblo en las naciones más ilustradas en el mundo ${ }^{4}$. En dicha nota se expresa de manera explícita el pensamiento desarrollista estadounidense, el ideal de progreso de los padres fundadores y de los evangelistas, ingleses y norteamericanos, del siglo XVIII.

No era la primera vez que Restrepo tenía contacto con Barber, en la carta del 18 de enero de 1923, el ministro evangélico le recuerda que le visitó un año atrás (principios de 1922) y que le agradeció a nombre de la misión presbiteriana sus luchas a favor del matrimonio civil. De manera implícita, el misionero Barber pide a Restrepo su ayuda para que el educador protestante Webster E. Browning dirija una charla en el Club Unión. Browning, había sido invitado por algunos ciudadanos a hablar delante del pueblo en el salón de la Universidad de Antioquia.

\footnotetext{
${ }^{2}$ Martínez Silva, Carlos. Puente sobre el abismo (Bogotá: Imprenta de La Luz, 1897).

${ }^{3}$ Ibid., p. 22.

${ }^{4}$ Colección Archivo Personal Carlos E. Restrepo, correspondencia recibida, 21 de diciembre de 1922.
} 
Según el testimonio del propio Browning, tanto las reuniones en la Universidad de Antioquia como en el Club Unión se hicieron y tuvieron muy buena asistencia. El libro Modern Missions on the Hispanish Main: Impressions of protestant Work in Colombia and Venezuela, escrito por W. Reginald Wheeler y por Browning, describe con estas palabras las reuniones en el exclusivo lugar de la élite de Medellín y en la Universidad de Antioquia:

\begin{abstract}
Nosotros hablábamos cada noche en la pequeña capilla protestante y toda la ciudad sabía quiénes éramos y qué hacíamos. Sin embargo, se nos extendió antes [que las conferencias en la Universidad de Antioquia] una invitación para hablar en el Club Unión bajo el tema 'La vida universitaria en los Estados Unidos'. Aceptamos esta invitación y un expresidente de la República presidió y presentó al orador. Cerca de cien estudiantes y hombres representativos de la ciudad estaban presentes y la reunión se llevó a cabo sin la menor fricción o malentendido. [...] Hubo ciertas dudas en las mentes de los hombres que estaban promocionando el asunto en cuanto a la actitud que podría asumir el arzobispo, se sabía que podía dar órdenes de cierre de la Universidad a las conferencias, o, al menos, prohibir a los fieles católicos que asistieran.
\end{abstract}

Sin embargo, la noche vino y se fue, y unas quinientas personas estuvieron presentes en la conferencia, la mayoría de ellos estudiantes de la universidad junto a un grupo liberal de hombres y mujeres de las principales familias de la ciudad. El expresidente Carlos E. Restrepo asistió, junto a su familia; un hermano del actual presidente también estuvo presente; y los más exclusivos círculos sociales de la ciudad estuvieron representados ${ }^{5}$.

Modern Missions on the Hispanish Main fue publicado en 1925, lo que indica que de la reunión en el Club Unión también hizo parte un hermano del presidente Pedro Nel Ospina. Pero no solo el matrimonio civil y la libertad de opinión fueron preocupaciones de Carlosé, el 9 de diciembre de 1921 la comisión Evangélica reunida en Medellín lo saludó y agradeció por “[...] su actitud tan delicada en pro de la libertad religiosa que está amparada por las leyes de la Nación”.6.

\title{
Tolerancia religiosa y separación religión-política, banderas del republicanismo
}

La inquietud de Restrepo por la cuestión religiosa venía de tiempo atrás. Veinte años antes de las Conferencias en el Club Unión y en la Universidad de Antioquia, en una reunión de notables convocada por el señor Restrepo, con el fin de acordar con los miembros de los diversos partidos bases para trabajar en las reformas que a su criterio necesitaba el país, se determinó la conformación de una Junta de Conciliación. Esta Junta publicó un documento que proponía el acercamiento entre partidos y una reforma constitucional. El punto F de dicho texto decía: "Impedir -por medio de una prudente tolerancia a todos los cultos que tengan por base la moral cristiana-, que en

\footnotetext{
${ }^{5}$ Browning, Wester E. y Wheeler, W. Reginald. Modern Missions on the Spanish Main. Impressions of Protestant Work in Colombia and Venezuela (Philadelphia: The Westminster Press, 1925), pp. 155-156. 
el país vuelvan a enardecer las pasiones políticas con motivo de la cuestión religiosa, de manera que nadie sea molestado en Colombia por sus opiniones y prácticas en esta materia. Y reconocer que la religión católica es la de la mayoría de los colombianos"7. El carácter conciliador y elitista de la junta se nota al conocer su cuerpo de oficiales: Carlos E. Restrepo, presidente; Fidel Cano, vicepresidente y Mariano Ospina Vásquez, secretario.

Para Restrepo, la reforma constitucional y el progreso de la república estaban por encima de las ideas religiosas. En una carta del 14 de mayo de 1909, dirigida a Juan C. Correa y Apolinar Mesa, miembros de la Unión Republicana de Amagá, el Dr. Carlosé expresa la necesidad de salvar la patria y la república, si es necesario, uniéndose a liberales y, aún, a no católicos:

Que algunos de esos liberales no son católicos ¿Será necesario ser católico para defender la patria y salvar la república? A los próceres nadie les preguntó que opiniones políticas o religiosas tenían [...] Hoy también luchamos por la independencia-Entre aquellos próceres está la Legión Británica, casi toda protestante y nadie pensó entonces en rechazarla y nadie se atrevería hoy a negarles la gloria que les pertenece ${ }^{8}$.

Este tipo de expresiones recuerdan la tolerancia religiosa que en 1825 Francisco de Paula Santander demostró al recibir personalmente al señor James Thomson, agente de la Sociedad Bíblica Británica y Extranjera y la de buena parte del clero de la época y hombres del gobierno que junto a Thomson fundaron la Sociedad Bíblica de Colombia. Cien años después, quienes abrían las puertas a los protestantes ya no a nivel nacional, sino a nivel local como Antioquia, fueron prominentes conservadores: don Pedro Herrán, hijo del expresidente Pedro Alcántara Herrán, quien les alquiló una casa para los primeros cultos, y Carlos Eugenio Restrepo.

Un amigo de Carlosé, Francisco Escobar, le escribe desde Nueva York el 10 de junio de 1909, le pide el favor de hacerle llegar sus escritos sobre la no injerencia del clero en la política, "Yo, soy más católico que el Papa y no obstante no dejo de comprender la deplorable influencia que ejerce el clero cuando se inmiscuya en la política. A eso atribuyo parte considerable de la triste situación de muchos de los países en donde el clero, pretendiendo guiar al pueblo por el camino del cielo, lo lleva al abismo de la politiquería"

Puede suponerse entonces, que los negocios, los viajes y los estudios en los Estados Unidos de cierto grupo de la élite antioqueña propiciaron un clima de tolerancia en materia religiosa. Desde mediados de siglo un buen número de jóvenes de familias prestantes estudiaba en los Estados Unidos preferiblemente carreras técnicas. El

\footnotetext{
${ }^{7}$ Restrepo, Carlos E. Orientación Republicana, t. I (Bogotá: Biblioteca Banco Popular, 1972), p. 290.

${ }^{8}$ Colección Archivo Personal Carlos E. Restrepo, correspondencia enviada, 14 de mayo de 1909.

${ }^{9}$ Colección Archivo Personal Carlos E. Restrepo, correspondencia recibida, 10 de junio de 1909.
} 
expresidente Pedro Alcántara Herrán era su apoyo en ese país, algunos de ellos hicieron sus carreras en colegios y universidades protestantes ${ }^{10}$.

El ideal de lo práctico del que habla Frank Safford pasó de lo económico a lo cultural, la tolerancia religiosa hacía parte de la idea de progreso tan en boga en la época. Mientras que Chicago pasaba del gran incendio de 1871 a la Feria Mundial de 1893, Colombia caminaba entre la guerra por la educación del 1876 y la guerra de los mil días. Y esos conservadores históricos y republicanos de seguro miraban con algo de envidia al coloso del norte. Martínez Silva, por ejemplo, comprobó con sus propios ojos el asunto mientras fue canciller en los Estados Unidos, creía en el progreso y desarrollo de Colombia ${ }^{11}$.

Posiblemente a lo que se refería Francisco Escobar, cuando le pide a Restrepo sus opiniones sobre la no injerencia del clero, era al deseo que tenía Carlosé de una separación de la Iglesia y la política al estilo anglo:

Sueño con una completa separación entre la Iglesia y los partidos, como la que existe en Inglaterra [...] como la que existe en los Estados Unidos, donde las leyes y las costumbres han permitido que un Presidente protestante dirija al ilustre arzobispo Ireland el siguiente telegrama con motivo de la construcción de la Catedral de San Pablo: 'en este afortunado país nuestro, libertad y religión son aliados naturales y avanzan de la mano"12.

Según el historiador Iván Marín Taborda tres aspectos fueron centrales en la administración de Restrepo: la conciliación bipartidista, el librecambismo económico y la tolerancia religiosa ${ }^{13}$. Esto nuevamente entrelaza a la tolerancia con el progreso en su forma de liberalismo económico. Jorge Orlando Melo, Fernando Correa Uribe y hasta la página web de la presidencia de la República recuerdan las palabras que Retrepo no quería que se olvidaran, publicadas en La Organización, el 18 de julio de 1910:

Señores: Sin yo solicitarlo en manera alguna y sin méritos de mi parte, he sido nombrado presidente de la República.

Hasta ahora he sido conservador; pero en el puesto que se me ha señalado no puedo tener partido político; desde la presidencia yo no debo miraros sino como a compatriotas, con iguales derechos, que debo proteger, a los unos y a los otros. Soy antioqueño; pero como presidente de la República, no soy sino colombiano. Soy católico; pero como presidente, dándole a la religión las garantías y la

\footnotetext{
${ }^{10}$ Safford, Frank. El ideal de lo práctico. El desafio de formar una élite técnica y empresarial en Colombia. Traducción de Margarita González y María Victoria Gussoni (Bogotá: El Áncora Editores, 1989).

${ }^{11}$ Henderson, James. La modernización en Colombia, los años de Laureano Gómez, 1889-1965. Traducción de Magdalena Holguín (Medellín: Clío, Editorial Universidad de Antioquia, 2006), p. 37.

${ }^{12}$ Colección Archivo Personal Carlos E. Restrepo, correspondencia enviada, 18 de abril de 1909, part. IV.

${ }^{13}$ Taborda, Iván Marín. "La Hegemonía Conservadora", en Calderón, Camilo (ed.), Gran Enciclopedia de Colombia, t. II, Historia (Bogotá: Editorial Círculo de Lectores, 1991), p. 495.
} 
protección a que le ha dado lugar la Constitución Nacional, no puedo ser pontífice de ningún credo religioso, sino el garantizador de la libertad de las creencias, cualesquiera que sean, de todos los colombianos. Os suplico gravéis estas palabras en vuestra memoria ${ }^{14}$.

\section{Los conservadores y el clero ortodoxo critican a Carlos $\mathbf{E}$.}

Es por supuesto, en medio de su gobierno donde recibe las más duras críticas de sus contradictores. El presidente cree que aquellos que tiene fe en Dios no deberían utilizar sus creencias para los ataques políticos, en una carta a su hermano, sacerdote jesuita, Juan María Restrepo expresa, “[...] muchas dificultades he encontrado para el gobierno de esta tierra y no es entre ellas la menor la suspicacia y la calumnia aún de parte de aquellos que por sus creencias y convicciones estaban más obligados a evitarlas"15.

En una carta del 30 de abril de 1914 el presidente Restrepo le dice a su hermano Juan María, quien se encontraba en Roma, que a pesar de las buenas impresiones que en materia religiosa le haría conocer el obispo Perdomo “[...] sobran aquí quienes se quejen de mi Gobierno por el aspecto religioso: es que nuestras exageraciones suben a un punto que apenas pueden concebirse"16.

La correspondencia con su hermano muestra en Carlosé un hombre profundamente religioso y preocupado por su familia, siempre pidiendo sus oraciones mientras dirige la nación. En algunas de estas cartas defiende su orientación republicana bipartidista y explica las, que dice son, calumnias que se disparan contra él:

Haces bien en no creer el sinnúmero de calumnias que la pasión política forja contra mí, al darles crédito me tendrías por ladrón, excomulgado y masón, que con tales calificativos me obsequió el clero de Pasto [...] ante la espinita que tienes porque coloco liberales, mira como te expongo el caso con toda franqueza y verdad. Los ramos del Gobierno Guerra e Instrucción Pública están dirigidos por católicos y conservadores a toda prueba. En los otros he colocado bastantes liberales, primero por la justicia intrínseca que hay en que ellos participen de los puestos públicos; y en segundo lugar porque es mejor tenerlos allí que en los campamentos ${ }^{17}$.

Tildar a Carlos E. de masón no era novedad ni exclusividad del clero de Pasto, un año atrás el cura de Jardín lo había hecho desde el púlpito. La respuesta del Dr. Restrepo fue enfática: "Me califican de masón por estar en contra de la mezcla religión y política":

\footnotetext{
${ }^{14}$ Correa Uribe, Fernando. Republicanismo y reforma constitucional (Medellín: Facultad de Ciencias Sociales y Humanas, Universidad de Antioquia, 1996), p. 159.

${ }^{15}$ Colección Archivo Personal Carlos E. Restrepo, correspondencia enviada, 23 de agosto de 1911.

${ }^{16}$ Colección Archivo Personal Carlos E. Restrepo, correspondencia enviada, Carta a Juan María Restrepo, Bogotá, 30 de abril de 1914.

${ }^{17}$ Colección Archivo Personal Carlos E. Restrepo, correspondencia enviada, 26 de julio de 1913.
} 
[...] se me ha dicho que el Sr. Cura de esa parroquia usando o abusando de la palabra de Dios había dicho que yo era masón; quizá en los mismos momentos en que lo hacía, acababa yo de recibir el Cuerpo Caritativo de ese mismo Dios; de modo que contra el testimonio del Sr. Cura, por respetable que sea, en contra de mi ortodoxia, puedo yo presentar el de mi conciencia y el de Dios [...]. Por lo demás, mi propaganda actual de que el clero no se mezcle en la política de partido, es un servicio que le estoy prestando al catolicismo, pues al mezclarse, lo desacredita sus ministros ${ }^{18}$.

La idea de separar lo político de lo religioso, porque lo espiritual es más sublime que lo terrenal y porque se quiere conservar el alto y divino puesto de las creencias y del sacerdocio, se encuentra en la mayoría de los escritos republicanos. El Boletín electoral Unión Republicana publica en mayo de 1911, en concordancia con las ideas del presidente:

El republicanismo pide á los católicos exagerados que concedan á sus adversarios religiosos el derecho de existir, de pensar y de hablar, que les ha dado la naturaleza, porque el desconocimiento de estos derechos, aunque sea para una pequeña porción del pueblo colombiano, sería una injusticia, origen de guerras civiles y desgracias para la Patria ${ }^{19}$.

\section{Sacar la política de las iglesias}

Al seguir este orden, tal vez lo más complicado desde la teoría del republicanismo fue la idea de separación Iglesia-política. Pues a diferencia del principio liberal separación Iglesia-Estado, los republicanos pedían la no injerencia de la Iglesia en la política, no necesariamente en el Estado. Unión Republicana lo recuerda así:

Principió cuando el Dr. Restrepo escribía su carta política al Dr. A. J. Uribe, época en que el Dr. Restrepo luchaba á brazo partido y en guerra franca contra el despotismo de los mismos que hoy pretenden haceros comulgar con ruedas de molino. Entonces se dijo: separación de la Religión y la política, -eso decimos hoy-, pero nunca de la Iglesia y el Estado porque jamás osaremos profanar el credo de nuestras convicciones más íntimas. Y ahora cuando está sobre el tapete social la cuestión político-religiosa, acerca del sufragio para los sacerdotes, solo hemos dicho: como de dos males el menor, también entre dos bienes el mayor para no desvirtuar el principio de conciencia y de razón. $\mathrm{Si}$ es verdad los ministros del culto católico tienen ese derecho y pueden ejercitarlo -el derecho al sufragio- pero con tal práctica maltratan nuestras creencias religiosas ¿Por qué no despreciarán esta ventaja mediocre si en cambio la Religión del Crucificado queda muy arriba, flotando por sobre todas las revoluciones humanas? Y decimos más: mientras los guardianes de nuestra fé religiosa continúen prestando el apoyo de su elevada dignidad á los partidos políticos, aquéllos vendrán á menos y el partido que tal maridaje necesitó, vivirá impotente; al fin irá calando en la conciencia del pueblo colombiano, que

\footnotetext{
${ }^{18}$ Colección Archivo Personal Carlos E. Restrepo, correspondencia enviada, 10 de abril de 1909.

19 “Boletín electoral núm. 1”, Unión Republicana, Medellín, 18 de mayo de 1911, p. 1.
} 
su fé católica no es arma de combate en las luchas apasionadas de la política, ni mucho menos artículo cotizable en el mercado diario ${ }^{20}$.

El presidente Restrepo trataba también de ser claro y no insistir en la separación Iglesia-Estado, hablaba de la separación de la Iglesia y los partidos, pues encajar a la Iglesia católica en un partido político haría que la religión pase por el fango y las veleidades por el que atraviesan las facciones políticas. Para Carlosé, el partido político es una secta y la iglesia es algo universal. En una exposición que hace para presentar a la Santa Sede defiende el hecho de que no católicos hagan parte de la Unión Republicana, "Es de notarse que algunos de los liberales que se han adherido a la Unión Republicana no son católicos; pero se han convencido del hecho social, de que, siendo esta religión la de la mayoría del pueblo colombiano, merece respeto, acatamiento y especial protección" ${ }^{21}$. Estas últimas palabras corroboran el ideario de los republicanos y aun de los conservadores históricos de continuar con el Concordato de 1887, con el propósito de mantener buenas relaciones con la Iglesia.

\section{La constitución política como punto de apoyo para los no católicos}

No obstante para el republicanismo, la Constitución estaba por encima del Concordato. El artículo 40 de la Reforma Constitucional de 1910 aclaraba, "En todo caso de incompatibilidad entre la Constitución y la ley se aplicarán de preferencia las disposiciones constitucionales". Los protestantes que buscaban legalizar sus matrimonios se amparaban en la Constitución y en la Reforma de 1910 y no en el Concordato $^{22}$. Y el artículo 39 de la Constitución de 1886 reza "Nadie será molestado por razón de sus opiniones religiosas, ni compelido por las autoridades a profesar creencias ni a observar prácticas contrarias a su conciencia"23. El misionero Browning recuerda que un grupo de ciudadanos de influencia hacen una petición al Congreso para que los matrimonios civiles ya celebrados por los jueces sean válidos. Dice Browning que entre dicho grupo se encontraba la firma de un expresidente, todo apunta a que era Carlos E. Restrepo. Al parecer el resultado de esta petición fue la Ley Concha sobre el matrimonio civil de los apóstatas. El apoyo de Carlos E. y la Ley Concha aumentaron el número de matrimonios en la Iglesia Presbiteriana de Medellín y varias parejas de Dabeiba venían a casarse en la capital.

\footnotetext{
${ }_{20}$ Jaramillo, Mariano. "Conferencia leída en el Comité Electoral Republicano”, Unión Republicana, Medellín, 25 de mayo de 1911.

${ }^{21}$ Restrepo, Carlos E. Antes de la presidencia (Medellín: Imprenta Departamental de Antioquia, 1982), p. 167.

${ }^{22}$ Acevedo González, Yudian Luz. "Libertad de conciencia en los contrayentes de matrimonio civil. Los casos de simpatizantes en Líbano, Baraya, y el de presbiterianos en Medellín, Ca. 1894-1919”, http:// historiayespacio.univalle.edu.co/index.php/historiayespacio/article/view/2781 (20 de noviembre del 2009).

${ }^{23}$ Secretaría General de la Alcaldía Mayor de Bogotá D.C. Constitución Politica de Colombia de 1886, http://www.alcaldiabogota.gov.co/sisjur/normas/Norma1.jsp?i=7153 (2 de noviembre del 2014).
} 
Fernán González recuerda en su libro Poderes enfrentados, que en 1920 se presentó en Medellín un incidente por el matrimonio de protestantes que daría lugar a la llamada Ley Concha, sancionada por el Congreso Colombiano como la Ley 54 de 1924, siendo presidente Pedro Nel Ospina. "Esta ley obligaba a apostatar públicamente a los bautizados católicos que querían contraer matrimonio civil”"24. Yudían Acevedo señala que esta coyuntura tiene su nudo en el matrimonio de Gilberto Rave, un rebelde liberal protestante, que aunque bautizado católico manifestaba que no podía casarse ante un Párroco porque no se lo permitían sus ideas y Ernestina Durier, hija de misioneros. Con el coraje de Rave, la petición al Congreso y la Ley Concha, los matrimonios entre protestantes se dispararon. En 1920, la pequeña congregación presbiteriana de Medellín registró ocho uniones civiles ${ }^{25}$.

La familiaridad del ahora expresidente Restrepo con los no católicos si hizo notar también la celebración de la Primera Convención Evangélica Nacional. A realizarse en Medellín en julio de 1926, provocó severas protestas por parte del clero, de destacadas personalidades de la vida antioqueña, así como una manifestación popular. Yudian Acevedo, hace un balance de la convención en su artículo "Identidad cultural y organizacional protestante a través de la Primera Convención Evangélica de Colombia, Medellín, 1926”26. De acuerdo a la investigación de Acevedo, el obispo José Manuel Caycedo tuvo el apoyo, en su intento de frenar la realización de dicho evento, de parte de destacados políticos y comerciantes de la época, entre otros, Carlos Vásquez, Alejandro Botero, Luis Navarro Ospina y Mariano Ospina Pérez.

La manifestación católica contra el Congreso protestante se realizó el lunes 19 de julio de 1926, congregó alrededor de 10.000 hombres (mujeres y niños no estaban invitados). La juventud católica tuvo una participación protagónica. El periódico La Defensa publicó ese día una edición extraordinaria para repartir gratis con el titular en primera página: "Grandiosa manifestación católica. Hoy sabrán los protestantes con cuántos católicos cuenta Medellín”.

Según la descripción del periódico, a las cinco de la tarde se comenzó a congregar la multitud en el Parque de Bolívar alrededor de la estatua del libertador. Desde una casa en la esquina de Junín con Caracas el joven entusiasta católico Carlos A. Agudelo pronunció un discurso muy aplaudido, luego los manifestantes se dirigieron a la gobernación. El periódico informó que ese mismo día en las horas de la mañana salió una resolución de la administración departamental por medio de la cual se prohibía la realización del Congreso ${ }^{27}$.

\footnotetext{
${ }^{24}$ González, Fernán. Poderes enfrentados: Iglesia y estado en Colombia (Santafé de Bogotá: Cinep, 1997), p. 274.

${ }^{25}$ Acevedo, Yudian Luz. Libertad de conciencia en los contrayentes de matrimonio civil. Los casos de simpatizantes en Libano, Baraya, y el de presbiterianos en Medellin, Ca. 1894-1919, http://historiayespacio. univalle.edu.co/index.php/historiayespacio/article/view/2781.

${ }^{26}$ Acevedo, Yudian Luz. "Identidad cultural y organizacional protestante a través de la Primera Convención Evangélica de Colombia, Medellín, 1926”, en Utopía Siglo XXI, vol. II, núm. 10, Medellín, Universidad de Antioquia, enero-diciembre de 2004.

27 “Grandiosa manifestación católica. Hoy sabrán los protestantes con cuántos católicos cuenta Medellín”, La Defensa, Medellín, 21 julio de 1926, p. 3.
} 
El misionero Alexander Allan, uno de los promotores del evento visitó entonces al expresidente Carlos E. Restrepo. Restrepo se había mostrado favorable a la celebración de conferencias públicas dirigidas por el misionero en Bogotá en la época de su gobierno. No obstante, fue gracias a la ayuda prestada por el alcalde de Medellín, Nicolás Vélez, que el Congreso pudo realizarse. Dice Alexander Allan,

Me acuerdo haber visitado, con un compañero, la misma noche, al expresidente de la República doctor Carlos E. Restrepo, a pedir su consejo. Nos manifestó que deberíamos telegrafiar al ministro de gobierno en Bogotá, pidiendo garantías. Le agradecimos mucho su buena voluntad, pero recordando las fiestas que hay en Bogotá a raíz del 20 de julio, y sabiendo por experiencia que las respuestas de Bogotá no siempre son inmediatas, resolvimos buscar una solución más rápida en aras de la economía, poniéndonos en contacto inmediato con el alcalde de Medellín ${ }^{28}$.

Aunque poco pudo hacer el Dr. Restrepo queda claro que aconsejaba a los no católicos y que la manifestación antiprotestante le dejó un sinsabor. En carta escrita a su amigo, el escritor y educador, Tomás Rueda Vargas el 13 de agosto de 1926 expresa:

Es preciso ver como en las poblaciones pequeñas se está sustituyendo del todo el predominio de la autoridad civil por la de los curas párrocos, que están estableciendo un poder temporal e incontrovertible porque se visten con el manto espiritual. Si usted hubiera visto desfilar por las calles de esta ciudad la manifestación católica para impedir la reunión del Congreso protestante, se hubiera quedado pasmado y aterrado; aquello era una procesión de fanáticos, de banderas desplegadas, de gritos ahogados en ira y en fe, de ojos encarnecidos y de brazos palpitantes, prontos a herir por sus creencias. De modo tal que uno llega a pensar que tanto el gobierno departamental como el nacional tienen la excusa de que quizá evitaban una nueva hecatombe de hugonotes, cuando violaron tan claramente la constitución, las conveniencias internacionales al prohibir la reunión de ese Congreso, el que - por lo demás- se celebró privadamente y sin que hasta ahora se sepa que hayan perdido nada ni las buenas costumbres ni las creencias de nuestros compatriotas ${ }^{29}$.

\section{La violencia religiosa, una preocupación constante de Carlos E.}

Como puede deducirse de la primera parte de la nota anterior, el Dr. Restrepo está preocupado por la mezcla de poderes, básicamente le molestaba que los sacerdotes ocuparan el poder civil. Según sus postulados eso podía llevar nuevamente a una guerra de tintes religiosos:

Desde hace muchos años vengo meditando y diciendo los graves temores que abrigo sobre el futuro de Colombia, procedentes de la cuestión religiosa, que se va creciendo, agrandando y agravando lentamente, sin que se vea otra solución

\footnotetext{
${ }^{28}$ Allan, Alexander. Recuerdos. El protestantismo en Colombia, 1910-1945 (Medellín: Tipografía Unión), p. 33.

${ }^{29}$ Restrepo, Carlos E., Op. cit., p. 205.
} 
que la misma indicada por usted y temida por mí, y es una guerra de religión, en la que si triunfa el lado del clero se solidificará hasta lo indecible su predomino sobre el poder civil; y si triunfan los contrarios tendremos épocas de estúpida persecución antirreligiosa, como ya las ha tenido Colombia, como las tuvo Ecuador y como las tiene hoy en forma palpitante el desgarrado México ${ }^{30}$.

Los temores del Dr. Restrepo no eran infundados, se basaban en la experiencia de un hombre que había batallado con el asunto por lo menos los últimos treinta años. Su padre, don Pedro Antonio Retrepo, pasó de ser liberal a conservador ya que no apoyaba el anticlericalismo de muchos de sus copartidarios. Además, Restrepo tenía una mirada más alta del asunto, una visión latinoamericana, persecuciones contra los clérigos y la Iglesia de Roma en el gobierno de Eloy Alfaro y la guerra de cristera que empezaba en México, donde el grito ;Viva Cristo Rey! tenía tanto de terrenal como de espiritual.

En un intento por recuperar los principios republicanos Carlosé hace parte integral del cambio de régimen, del amanecer de la República liberal, y es designado el primer Ministro de Gobierno de Enrique Olaya Herrera. Una guerra religiosa a nivel general en todo país parecía detenerse. Pero quedaban rebuscos, odios de vieja data, especialmente en aquellos lugares de mayor intransigencia. El violento discurso, de años y años, pronunciado por clérigos y políticos tendría sus efectos. El grito de los liberales de Capitanejo, Santander y de la región de García-Rovirá se escuchaba en buena parte de ese país campesino "godos miserables, somos nosotros quienes estamos ahora en el poder"'31.

Según la Doctora en Derecho de la Universidad de Zaragoza, Melba Luz Calle, la guerra que vivió Boyacá y Santander en la República liberal fue una guerra políticoreligiosa, donde mataban sacerdotes y amenazan a otros como al de Boavita, Boyacá. Las masacres y el despojo de tierras a campesinos conservadores no se hicieron esperar después de la llegada de Olaya Herrera. Algo parecido ocurrió entre 1948 y 1953, en medio de la violencia bipartidista, donde los evangélicos, sobre todo en los campos, vivieron una persecución político-religiosa que les recordaba aquellas antiguas historias bíblicas, entre otras, la del cautiverio judío en Babilonia.

\section{A manera de conclusión}

Buena parte de la historiografía colombiana se ha ocupado de las relaciones IglesiaEstado. Uno de los aspectos que más se ha resaltado es la integración entre el Partido Conservador y la Iglesia católica romana, una común unión de principios que desde mediados del siglo XIX se notaba en los ideales del conservatismo. Quizás la misma historia del partido (con sus fundadores José Eusebio Caro y Mariano Ospina Rodríguez, y las evidentes relaciones de los tales con el catolicismo) puso un velo en

\footnotetext{
${ }^{30}$ Ibid., p. 204.

${ }^{31}$ Henderson, James, Op. cit., p. 270.
} 
la realidad social que, a pesar de los esfuerzos hechos por estudiosos del tema como Fernán González y Carlos Arboleda Mora, no permite observar con toda claridad el fondo de la misma. Pareciera que mientras el liberalismo del siglo XIX tuvo sus variantes (draconianos, gólgotas, mosqueristas, radicales, y demás), el conservatismo fue homogéneo gracias a su avenencia con la Iglesia.

El republicanismo fue un intento de cierta élite ilustrada, de finales del siglo XIX y principios del XX, que veía en los partidos políticos, liberal y conservador, a grupos sectarios que no podían valorar al otro sino convertirlo. Carlos E. Restrepo como líder del movimiento asumió, según sus palabras, el sacrificio de la presidencia. Al tratar de conciliar a liberales y conservadores, uno de los principales fundamentos del republicanismo fue la tolerancia en materia religiosa. No debía volver a presentarse una guerra por este motivo.

La idea de este escrito es aumentar el tamaño del lente para notar una realidad más específica. Aquella en la que las relaciones personales (por ejemplo las de Carlosé con sus amigos liberales y sus conocidos misioneros) crean otra atmósfera política, diseñan un discurso más racional y tolerante, menos fanático, para decirlo en palabras de la época.

Utilizar la correspondencia personal de Carlos E. Restrepo como la principal fuente presentó unas ventajas incomparables. Las cartas a sus amigos y familiares revelan ciertos sentimientos e ideas difíciles de encontrar en la prensa y los escritos oficiales.

Los republicanos se fueron quedando solos en su intento, las pasiones normalmente le ganan al juicio, su candidato a la presidencia de 1914 no alcanza ni la mitad de los votos del ganador. Tolerancia, respeto y acuerdo, son palabras que nunca parecen estar de moda. Quizá el mayor aporte que puede hacer hoy el republicanismo, sigue siendo el más difícil de explicar y de aplicar: separar la religiosidad de la política, pero no del Estado. La línea es tan débil y se mueve tan fácil que, al parecer, solo el constante esfuerzo intelectual puede crear alguna conciencia.

\section{Bibliografía}

\section{Fuentes primarias}

\section{Correspondencia}

Colección Archivo Personal Carlos E. Restrepo. Biblioteca Central Universidad de Antioquia. Correspondencia enviada.

Colección Archivo Personal Carlos E. Restrepo. Biblioteca Central Universidad de Antioquia. Correspondencia recibida. 
Tolerancia religiosa en el republicanismo. El caso de Carlos E. Restrepo

\section{Libros}

Browning, Wester E. y Wheeler, W. Reginald. Modern Missions on the Spanish Main. Impressions of Protestant Work in Colombia and Venezuela. Philadelphia: The Westminster Press, 1925.

Martínez Silva, Carlos. Puente sobre el abismo. Bogotá: Imprenta de La Luz, 1897.

Restrepo, Carlos E. Antes de la presidencia. Medellín: Imprenta departamental de Antioquia, 1982.

Restrepo, Carlos E. Orientación Republicana, t. II. Bogotá: Biblioteca Banco Popular, 1972.

Allan, Alexander. Recuerdos. El protestantismo en Colombia, 1910-1945. Medellín: Tipografía Unión, s. f.

\section{Prensa}

La Defensa, Medellín, 1926.

Unión Republicana, Medellín, 1911.

\section{Fuentes secundarias}

\section{Libros}

Arboleda Mora, Carlos. Guerra y religión en Colombia. Medellín: Universidad Pontificia Bolivariana, 2005.

Correa Uribe, Fernando. Republicanismo y reforma constitucional. Medellín: Facultad de Ciencias Sociales y Humanas, Universidad de Antioquia, 1996.

Cortés, José David. Curas y politicos, mentalidad religiosa e intransigencia en la diócesis de Tunja, 1881-1918. Bogotá: Ministerio de Cultura, 1998.

González, Fernán. Poderes enfrentados: Iglesia y estado en Colombia. Santafé de Bogotá: Cinep, 1997.

Henderson, James. La modernización en Colombia, los años de Laureano Gómez, 1889-1965. Traducción de Magdalena Holguín. Medellín: Clío, Editorial Universidad de Antioquia, 2006.

Moreno Palacio, Pablo. Por momentos hacia atrás... por momentos hacia adelante. Una historia del protestantismo en Colombia. Cali: Universidad de San Buenaventura, 2010 . 
Safford, Frank. El ideal de lo práctico. El desafio de formar una élite técnica y empresarial en Colombia. Traducción de Margarita González y María Victoria Gussoni. Bogotá: El Áncora Editores, Universidad Nacional de Colombia, 1989.

\section{Capítulos de libros}

Plata Quezada, William. "De las reformas liberales al triunfo del catolicismo intransigente e implantación del paradigma romanizador", en: Bidegaín, Ana María (Dir.), Historia del cristianismo en Colombia. Bogotá: Taurus.

Rodríguez Sanín, Javier Augusto. "Protestantismo y política en Colombia (18561930)", en Coloquio El Cristianismo en Colombia en el Siglo XX, Bogotá: Universidad Nacional de Colombia, 1994.

Taborda, Iván Marín. "La Hegemonía Conservadora”, en Calderón, Camilo (ed.), Gran Enciclopedia de Colombia, t. II, Historia. Bogotá: Editorial Círculo de Lectores, 1991.

\section{Artículos en revistas}

Acevedo, Yudian Luz. "Identidad cultural y organizacional protestante a través de la Primera Convención Evangélica de Colombia, Medellín, 1926”, en Utopía, Siglo XXI, vol. II, núm. 10, 2004.

\section{Publicaciones en Internet}

Acevedo, Yudian Luz. Libertad de conciencia en los contrayentes de matrimonio civil. Los casos de simpatizantes en Libano, Baraya, y el de presbiterianos en Medellín, Ca. 1894-1919, http://historiayespacio.univalle.edu.co/index.php/historiayespacio/ article/view/2781. 